\title{
Research on the Application of the Mind Map in English Grammar Teaching
}

\author{
Ling Wang \\ School of Foreign Languages, Nanchang Normal University, Nanchang, China
}

\begin{abstract}
English grammar is an essential part of English learning, and it is the basis for students to grasp English. English grammar learning has become a major problem for high school students in the process of English learning. Therefore, it is particularly important to find an effective way to help students master English grammar. Mind map, which is a tool to express divergent thinking, can help people rationally utilize man's left and right brain to improve people's creativity and memory. Mind map has drawn Chinese educator's more and more attention. Based on the basic goals and requirements of the new nation curriculum reform, this paper will focus on the application of Mind map in English grammar teaching, and whether applying Mind map in English grammar teaching can improve students' interest and efficiency in grammar learning, thus becoming a feasible teaching method in the process of grammar teaching. Through this study, this paper draws a conclusion that the application of Mind map in English grammar can enhance the students' initiative, promote the students' interest in learning, the efficiency of learning and the ability of grasping grammar knowledge.
\end{abstract}

Index Term — mind map, English grammar teaching, application

\section{INTRODUCTION}

Mind map is the expression of divergent thinking, so it is also the natural function of human thinking. This is a very useful graphic technique and a universal key to unlock the brain's potential. Mind map can be applied to every aspect of life. It does favor on students' learning abilities and makes students' modes of thinking clear, and then ameliorate people's behavior. A Mind map is a diagram which is used to visually organize information. It is hierarchical and shows relationships among pieces of the whole. It is often created around a single concept, drawn as an image in the center of a blank page, related to representations of ideas such as images, words and parts of words are added (Buzan, 1993).

The linguist Wilkins (1987) once said, "Without grammar, there are few things that people can express, without words, and people can't express anything." This is enough to illustrate the importance of grammar learning. In the process of mastering the knowledge of English listening, speaking, reading and writing, people must learn English grammar firstly. Only if people learn English grammar knowledge well, can they accurately express their ideas with each other in English. In reading, we are able to comprehend the structure and the central idea of the article, and then form reading ability. In writing, processing the basic grammatical knowledge, people can convey personal thoughts and feelings accurately and effectively.

English grammar is one of the compulsory language abilities. It is an important learning stage for English learners in senior high school. In some ways, high school English grammar is difficult for students to master. Because it is complicated and numerous, distributed in the textbook, which is challenging for students. Mind Map, which is a very useful graphic technology, can help students to express the divergent thinking, to explore the potential of the brain. Mind map can effectively focus the thinking of English learners on the overall framework of the concepts. Mind Map which is decorated with colors, pictures, code, multi-dimension, can lessen the vacuity of traditional grammar teaching and arouse the enthusiasm of students. On the other hand, Mind Map can help students to remember and understand grammar, be more convenient to extract the information of grammar, improve the efficiency of grammar learning.

\section{LITERATURE REVIEW}

\section{A. The Foreign Study of Mind Map}

The study of Mind Map in foreign countries was earlier, the 1960s Donny Bozing (Tony Busan) began using it to help people with learning disabilities optimize their notes and improve their memory. In 1971, he presented the concept of divergent thinking and published more than 20 books, including the Mind map, Mind mapping, divergent thinking. These books have been translated into dozens of languages and published in more than 50 countries. The application of Mind map is widely used for personal use, family use, educational use, business and professional use, and future use. In personal use, it can be used for self-analysis, problem solving, Mind Map diary and so on. In the family, there are some applications. And it is widely used in the field of education. Graham, dean of the Department of Chemistry at the Shervin University of Science and Law in the UK, drew a chemical kinetic Mind map used to prepare all the chemistry classes for the seniors in the college entrance examination. And the teacher used it to prepare the lectures, while the 
students used it to prepare for the lectures.

Ertug Evreklia, Ali Gunay Balima, Didem Inela (2009) claimed that Mind map could improve the efficiency of conducting constructive science and technology and help students in different stages; however, Mind map method was not appropriate for some science topics.

Özgül Keleş (2012), Elementary Teachers' Views on Mind Mapping, was supported his views by interviewing teachers. His results showed that introducing Mind maps into instruction helped teachers improve their instruction, planning and evaluating lessons; and make the lecture more entertaining. He proposed that the technique of using Mind map could be applied to more fields by analyzing its relationship with different variables, such as different courses and participants.

Ismail, Ngah and Umar (2010) insisted that the application of Mind map to the study of computer science could improve students' ability of programming, problem-solving ability and metacognitive level. Dhindsa and Kasim (2007), the application of Mind map to natural science in adult teaching, it was found that using the Mind map teaching graded higher than the traditional teaching method of student achievement, and Mind map method can minimize science academic achievement gender differences.

With the development of network technology, Mind map has become a very good e-learning tool. It can be used to increase the interest of learning, and to organize or guide the network content and documents better. British scholar Conole and Weller (2008) thought that Mind map serving as auxiliary tool of teaching design, Mind map could not only help designers realize anticipated target, but also help designers to better organize thoughts, share and discuss ideas in the design process as well.

\section{B. The Domestic Study of Mind Map}

The domestic research begins very lately. The research of the inland Mind Map in China mainly concentrates on: the ontology research of Mind Map, the research of the software and the method of Mind Map making, and the research of Mind Map in education and teaching field. The majority of those researches is the study of Mind map in education and teaching. While the application in English teaching is mainly in the fields of comprehensive research, vocabulary research and reading research. And there are few researches on listening and writing.

Wei Hongxia (2010) proposed that Mind map was helpful for students to exchange and cooperate with others, and it could boost their abilities of independent learning and thinking, improve their interest in learning English words in favor of the Mind map method.

Gu Xiujing (2016) stated that teachers introduced Mind map into English grammar teaching could not only to raise students' interest but also to improve their competence of grammar knowledge. She insisted that the leading role of teachers should be ensured, and students' role as active learners should be guaranteed should be guaranteed as well.

He Fangping (2013) claimed that using Mind map had good effect on senior vocabulary, grammar, reading and writing teaching. She supported the view that Mind map could help teacher prelect contents in the text with a scientific and effective method, help the students promote meaningful learning. In the meantime, she conducted experiments about introducing Mind map into teaching, to verify whether this can arouse students' interest and irritate students' initiative in learning. However, there are some shortcomings in her paper. Although she mentioned to some strategies likes principle, she didn't give concrete measures related to teaching. In other words, she couldn't give effective suggestions to the teachers and students.

\section{CURrent Situations of English Grammar Teaching in High Middle School}

\section{A. The Disadvantages of Traditional Grammar Teaching Methods}

In China, traditional grammar teaching mainly depends on translations, introductions, deductions. In the course of a traditional high school English grammar class, the teacher always plays as the main speaker explaining the grammatical rules of the English language, organizing teaching in his/her native language. And what students need to do is just listening and trying hard to memorize the grammatical rule and examples. It is too passive of students in this kind of teacher-centered class. It deprives students of chances to express their own thoughts (Nie Lifang, 2012). Teachers occupy dominant role to lecture the contents in the text, however, the students always be forced to take in grammar knowledge. We can't fail to notice this phenomenon that students are told to keep grammar knowledge in mind by practicing for a thousand times. Besides, grammar always was imparted to students by one simplex way. Meanwhile, they need to do a load of exercises including telling whether sentences follow grammar rules and then modifying them until sentences accord to the correct grammar rules. In other words, students are deprived of enthusiasm and passion in the class. It is not difficult to understand that why English grammar teaching is very dull and boring.

As for senior high school students, English is the second language that doesn't like the native language, so familiar to them. High school English grammar in some ways is complicated and enormous for the students. Especially the usage of Chinese differs from English among listening, talking, reading, writing. Due to the impact of the first language, students have some difficulties in the process of grammar learning. Lacking real language environment, the students have few occasions to communication with each other, to express their ideas in English in daily communication.

With an increasing number of scholars exploring and seeking better methods for education, there many researches come out, in those researches which are about new methods like situational approach, Communicative approach, 
Cooperative learning method.

Mind map is widely applied into extent aspects at aboard and home. In foreign countries, the application of Mind map in education has been popularized. In recent years, a few experts in China begin to take actions to put Mind map method into education. It goes without saying that more and more new techniques are to be involved in teaching and learning

\section{B. The Advantages of the Application of the Mind Map in Grammar Teaching}

Mind map is always decorated with colors, pictures, symbols, code and so on. With the aid of its features, teachers use Mind map to lecture lessons to make the lesson fun, to stimulate the students' interest in learning. While easily accepting the Mind map, the students learn the much more grammar.

The Mind map follows the features of the divergent thinking of the human's brain. It makes the students effectively input or output messages which are linked with some words. On the other hand, using this way to memorize or distill information, can cultivate students 'divergent thinking and creativity, and excavate their potential.

Teachers can use the Mind map to prepare lesson plans, to comb the overall framework of grammatical knowledge, to make the grammar in a clearer way to impart to students. Provided that students take notes about a single grammatical knowledge point with the traditional method, they can only remember one key word. If they take notes by using the Mind map, they will mention with the relative knowledge of one key word. By this way, the memory of key words will be clearer, and more fragrant.

Using Mind map to make notes--only remembering the relevant words, help students save a lot of time. What's more, students can save time by looking at related words in the Mind map and create a clear and more appropriate association between key words.

The brain tends to accept and memorize notes with visual stimulation, multiple colors and multi-dimensional Mind maps rather than monotonous and annoying notes.

Using Mind map in the process of teaching, we can comb a lot of knowledge points, so that to make points present to students in order. The grammar knowledge that students receive can be intuitive and visualized by using Mind map. The Mind map, which contains images, colors and lines, can effectively tease out the connections between the grammar knowledge points. The very common used Mind map in high school English teaching is the main tree and the comparison diagram, which can effectively find out the connections among a wide variety of knowledge points. To take an example, while interpreting the subjunctive mood, the teacher makes the knowledge and skill target according to the curriculum goal and the teaching material. Subsequently, the teacher assigns the task to the students, and lets the students preview the content of the knowledge point of virtual emotion by themselves before points are organized and summarized with the Mind map method. By drawing the Mind map of the main tree, students have entire grasp of the knowledge they learnt. Next, teachers further explain the subjunctive mood in the process of teaching, and then draw a Mind map to compare and sum up all of knowledge points. In the process of drawing such two different Mind maps, students naturally build the positive way of thinking.

Introducing the Mind map into teaching effectively, by combining the two different Mind maps of main tree maps and contrast diagrams, help students to integrate some fragmentary knowledge points with those resources, and help them to study systematically. At the same time, students can also form good habits of thinking and study in order that improve their learning efficiency.

It is helpful for students to use Mind map to complete the integration of grammar knowledge. The method of drawing Mind map can not only stimulate students' interest in learning, but also guide them to develop a habit of thinking actively and improve their understanding of knowledge content. For example, after grammar knowledge of subjunctive mood is taught to the students, they are divided into groups, and are required to observe and analyze the Mind map which made up of two different structures. At last, they are asked to finish the Mind map, which is used to sum up the knowledge points of the present subjunctive mood. Based on the results of the Mind map drawn by the students, the students are divided into groups to discuss and make corresponding comments; to understand and think about the mistakes, the advantages and disadvantages of the works, to understand and to digest the knowledge points explained by group members, to further deepen the important points and difficult points, and to consolidate the knowledge point step by step.

\section{The Application of the Mind MaP in English Grammar Teaching}

\section{A. The Relationship between Mind Map and English Grammar}

Buzan pointed out his concept of radiation tree and used a colorful, radial, tree like structure to describe keywords. He believed that although the "tradition" program forced readers to scan from left to right, from top to bottom, readers actually tend to scan the entire page in a non-linear way. Buzan's treatment also uses the prevailing hypothesis of cerebral hemisphere function to explain the effectiveness of the claimed Mind map for other forms of note making (Buzan, 1993).

Mind map is popularized by Buzan who claims that it is an enormous superior note-taking method. Through Mind mapping, people can develop their abilities in memory, brainstorming, learning and creativity (Igemann, 2008). "The research collects the data by using the experimental tools such as pretest-posttest, the questionnaire, teaching reflection 
and SPSS software for data analysis. Finally, the research found that Mind map in the grammar teaching had positive effect on arousing students' interest in learning grammar and improving their grammar learning efficiency, and it was feasible and effective to English teaching in some way." (Gu Xiujing, 2016)

According to Zhao, teachers can understand whether students understand the subject, if they can build the appropriate structure of new information by checking their Mind maps. Mind mapping is a note-taking, organizational technique, which allows individuals to "organize facts and thoughts" in a map format containing a "central image, main themes radiating from the central image, branches with key images and key words, plus branches forming a connected nodal structure" (Buzan, 1993). In addition, Mind map helps students absorb new information, think and develop their conceptual schema. Mind mapping is a technology to enhance creativity and promote personal learning (Mentol. Martinelli \&amp; Jones, 1999).

\section{B. The Application on the Mind Map in English Grammar Teaching}

Prepositions are a vital part of a sentence. They and other words are made up of one prepositional phrase that acts as a grammatical component, as an adverbial, a predicative, a complement, an attribute or a preposition object in the sentence. At the same time, the use of prepositions is also very flexible. A single preposition can express a variety of meanings, prepositions can be divided into time prepositions, place prepositions, way prepositions, causal prepositions, quantity prepositions and other prepositions. The main uses of prepositions are about time, direction, conduct, reason, method, quantity, etc. By using Mind map to classify all kinds of prepositions, students can learn prepositions with an easier and more scientific way. Just give an example, a teacher wants to interpret prepositions indicating a place.

When the teacher designs a Mind map, they firstly mark the topic "indicating place" at the center point on the blackboard. The preposition "at", "on", "in" is marked in the first branch. When the second branch expresses the use rules, the branch of "at" should explain the use rules of "at" in Chinese. And then, the third branch will further interpret the rules with one example sentence. In the process of drawing a Mind map, you can use one place which is familiar to student in the example sentence like "Her father works at Fudan University." Students can also use beautiful colors and graphics to make Mind maps richer and more attractive. Following those steps, students can summarize the grammar rules of other prepositions.

The topic of a Mind map is in the center, and the first branch is the preposition "at", "in" and "on". The secondary branch is the rule of use for each preposition and the next branch is some example sentences of the corresponding the use rule. Facing with a lot of prepositions, students often take a lot of time but get a lot of unsatisfactory results by using traditional methods--memorizing every formula. With the aid of Mind map, we can systematically summarize and memorize knowledge points. We can extract information more quickly and accurately.

The attributive clause is one of the difficult points in high school students' grammar knowledge learning. The attributive clause can be used to modify sentence composition of a subject, object and attribute in the whole sentence. Because of the characters of attributive clauses, it is challenging for students about the proper usage of the relative pronoun. In the process of distinguishing the relative pronoun of different components in the sentence, teachers can teach students to use Mind map to draw a diagram to clearly classify grammar rules. For example, "He is a man who/that wears a blue suit and a pair of sunglasses.". In this sentence, the attributive clause modifies the antecedent "man", so the word "who/that" serves as the relative pronoun. "The people whom/that you met in the campus yesterday are from American." The attributive clause, "you met in the campus yesterday are from American", modifies the antecedent "people". Therefore, in this sentence the relative pronoun is "whom/that". Using the way of drawing the Mind map, we can generalize and distinguish the relative pronoun of the subject, object and attributive, which acts as different components of the sentence. It can not only reduce the time of learning of attributive clause grammar knowledge, but also improve the learning efficiency. On the other hand, it allows students to participate more in the learning process, mobilize the interest of learning.

Mastering the grammar knowledge of the adverbial clause is unavoidable for high school students. The adverbial clause is divided into nine categories: adverbial clauses of time, adverbial clauses of places, adverbial clauses of condition, adverbial clauses of reason, adverbial clauses of concession, comparison of adverbial clauses, adverbial clauses of form, adverbials of purpose and adverbial clauses of result. Just take one sentence as examples. "When you come back, you'll find the appearance of the city greatly changed." In this sentence, the action of the main clause is followed by the introducer "when". "As time passed, things seemed to get worse." In this sentence, the clause is accompanied by the main sentence, with the introducer "as". If we use the Mind map to classify those adverbial clauses of time, like "when", "whenever", "as", "while", "now". As a result, the knowledge points of the adverbial clause of time can be collated, inducted, classified. Teachers draw Mind map with the characters of being clear and more concise to teach students. It is much easier for students to accept the adverbial clause of time grammar knowledge.

If a teacher introduces the adverbial clause of time to his students with Mind map method, he must firstly mark the topic "adverbial clause of time" at the center point. In the first branch, the introducer "when", "whenever", "as", "while" is written down. When the second branch expresses the rules of use, the branch of "when" should explain the use rules of "when" in Chinese. Then, the third branch will further interpret the rules with one example sentence. In the process of drawing a Mind map, you can use the example sentence like "He entered the room when the meeting was going on." Students can also use a kind of colors and graphics to decorate the Mind map to get a better memory of grammar knowledge. What's more, other adverbial clauses can be introduced by such method. 


\section{The Suggestions of Application of Mind Map in English Grammar Teaching}

In the application of Mind map in classroom teaching, students have more freedom to study independently. However, without enough preparations, the amount of homework and the time of collecting and sorting information may affect the completion of normal teaching tasks. Therefore, teachers can make use of the extracurricular time and classroom time to have students complete the preparatory work of Mind map before class time. For example, gathering and processing information can be completed before the class. At the same time, teachers can also enable students to complete the preliminary Mind map without guidance. The teacher communicates and discusses the achievements of students individually. And through classroom time, teachers will guide students to perfect the production of Mind map. In this process, teachers should pay attention to the guidance of students' deep thinking so that students can finally acquire complete knowledge system and mature research results.

Teachers can make full use of the teacher's leading role. The first reason is about students' different thinking patterns. The students draw different shapes because they possess their own different thinking modes. Therefore, teachers should give different guidance according to different students' learning styles, so that students can develop their vocabulary ability on the basis of improving their thinking ability.

Secondly, we need to adjust the differences maps for students. Because the Mind map and the traditional text information have different arrangement order and pattern, the initial drawing of the students will appear to be confused, and their works' difference is great. Regarding of those reasons, teachers should avoid making simple and uniform demands. That is to say, the teachers can show students the knowledge points with a variety of forms such as self-evaluation and mutual evaluation, evaluating the differences. Then, the teacher will ask the students to revise or redraw the Mind map and reflect on the learning content.

Thirdly, we need to monitor the effect of students' memory. The students' memory style is very different, some students' ability of memorizing is not good, the memory of things is lack of purpose, the ability of short memory is poor, and forgetting is fast. Teachers should monitor the learning effect of students against this problem. We can collect feedback information, or use tests to evaluate students' learning effect, find out the deficiencies in teaching and amend them in time.

\section{CONCLUSION}

In this study, the author finds that the Mind map is a useful and effective thinking tool, which can help students to memorize grammar knowledge and improve their learning efficiency. In the course of research, the author find that Mind map is not only a learning tool for students, but also a suitable teaching tool for teaching. As for teachers, they can use Mind map to prepare for many works. Mind map can be used for teachers in wide aspects, such as preparing for lessons, doing lesson plans, etc. Mind map method can also enrich and perfect the teachers' teaching skills. On the other hand, the author observed that it is useful to use the Mind map to organize the knowledge of each of the individual elements, especially in the refresher course. Using Mind map to comb and sum up the knowledge points. And then using lines to link knowledge points and difficult points, to reform stereoscopic connection. It will not only help students to make thinking visual, to clear the norm of exhibition now, and to have deep comprehension about the knowledge points.

Meanwhile, the author noticed that phenomenon that now there were some students drawing the painting of Mind map table with low confidence and they feared to make it in mess. The reason for such thought is drawing picture in the process with conflict psychology. It is suggested that teachers should operate much more group activities and encourage members in the group to discuss and ditch together, to learn from each other. The drawing of Mind map itself is a kind of art creation, and it doesn't need to satisfy the standards of beauty and ugliness; each of them is a result of the creation of the human being's brain. The author maintains that the application of Mind map should be emphasized. This kind of language teaching method should not be only applied in listening, speaking, reading and writing. The application value of Mind map should not be limited to this, and its application value in other subjects should be further studied.

\section{REFERENCES}

[1] Buzan Tony, Barry Buzan. (1993). The Mind Map book: How to use radiant thinking to maximize your brain's untapped potential. New York: Penguin Press.

[2] Conole, G., \& Weller, M. (2008). Using learning design as a framework for supporting the design and reuse of OER. Journal of Interactive Media in Education, 5, 1-13.

[3] Dhindsa, H. S. \& Kasim, M. (2007). Constructivist-visual Mind Map teaching approach and science, adult students achievement. METSMaC,: 357-372.

[4] Ertug Evreklia, Ali Gunay Balima, Didem Inela. (2009). Mind mapping applications in special teaching methods courses for science teacher candidates and teacher candidates' opinions concerning the applications. Social and Behavioral Sciences, 3, 93-94.

[5] Ismail, M. N., Ngah, N. A., \& Umar, I. N. (2010). The effects of Mind mapping with cooperative learning on programming performance, problem solving skill and metacognitive knowledge among computer science students. Journal of Educational Computing Research, 1, 35-61. 
[6] Mento, A. J., Martinelli, P. \& Jones, R. M. (1999). Mind Map in Executive Education: Application sand Outcomes. The Journal of Management Development, 2, 34-36.

[7] Novak J.D. \& D. B. Gowin.( 1984). Learning How to Learn. London: Cambridge University Press.

[8] Özgül Keleş. (2012). Elementary Teachers' Views on Mind Mapping. International Journal of Education, 3,25-26

[9] Slavin, R. E. (2004). Educational Psychology: Theory and Practice. Beijing: Peking University Press.

[10] Thorpe, M. (2008). Effective online interaction: Mapping course design to bridge from research to practice. Australasian Journal of Educational Technology, 1, 57-72.

[11] Wilkins. (1987). English Study, Foreign Language Study Institute.

[12] Wei hongxia. (2010). Application of mind mapping in English word teaching. Henan University, 12-14.

[13] Gu xiujing. (2016). Research on the application of mind mapping in the teaching of English grammar in senior high school. Shandong normal university, 25-26.

[14] He fangping. (2013). Research on the application of mind mapping in high school English teaching. Anhui normal university, 3-15.

Ling Wang was born in Jian, China in1967. She received her bachelor of Art degree in linguistics from Jiangxi Normal University, China in 1995.

She is currently an associate professor in the School of Foreign Languages, Nanchang Normal University, Nanchang, China. Her research interests include cross-cultural teaching and teaching methods.

Prof. Wang is a member of the Chinese Association of Foreign Language Teacher. 